\title{
CORRECTION
}

\section{Correction to: Hum Gene Ther Clin Devel 2017;28(1):17-27}

In the March 2017 issue of Human Gene Therapy Clinical Development (vol. 28, no. 1, pp. 17-27), the name of one of the coauthors of the article entitled "Good Laboratory Practice Preclinical Safety Studies for GSK2696273 (MLV Vector-Based Ex Vivo Gene Therapy for Adenosine Deaminase Deficiency Severe Combined Immunodeficiency) in NSG Mice” by Carriglio et al., was listed incorrectly.

"Draghici Elena" should have been listed as "Elena Draghici."

The online version of the article has been corrected to reflect this change.

The authors wish to apologize for the error. 